\title{
Information and knowledge sharing within virtual communities of practice
}

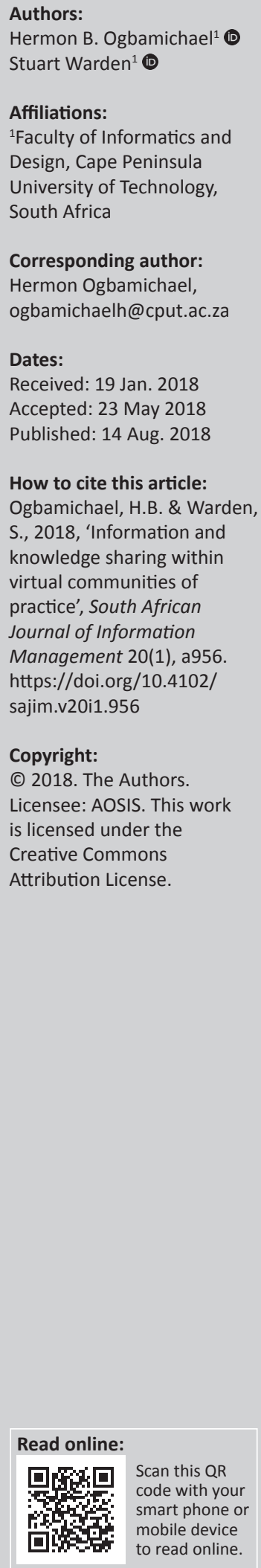

Background: The concept of a virtual community of practice (VCoP) emanates from the need to create a new mode of learning and knowledge development platform. It has also been found that highly structured forums are not always the best way to assist people to learn and improve their knowledge. The first author (main researcher) has limited background knowledge and professional practice in the area of VCoPs. Within this context, the investigation of the use of VCoPs to optimise knowledge sharing within stakeholders is the central theme of this research. The authors adapted the life cycle knowledge flow model and present an extended model that resulted after an empirical research was conducted with various VCoPs.

Objectives: The objective of this paper is to report on the research that, firstly, attempted to find a suitable model among all previous research conducted on knowledge sharing (management) and to create a new model that could be used to optimise knowledge sharing within VCoPs.

Method: In this research, a review of literature was used to define the main concepts of this research. A qualitative methodology was used. The responses received using two questionnaires were analysed to establish some premise, derived from the findings. The Miles and Huberman framework for qualitative analysis was also used to analyse the data set received from participants in the two questionnaires administered. This framework for analysis includes data reduction, data display, drawing and verifying conclusions.

Results: An extended life cycle knowledge flow model is proposed to optimise knowledge sharing within VCoPs.

Conclusion: A comprehensive knowledge flow model, namely the extended life cycle knowledge flow model, was found to be most suited from the literature. The analysis of two questionnaires, one administered in 2011-2012 and the other in 2016, led to the adaptation of the model to enhance knowledge sharing within VCoPs and, in turn, to develop and optimise knowledge sharing in enterprises.

\section{Introduction}

The concept of virtual communities of practice (VCoPs) originates from the need to create a new mode of learning and presented a specific form of knowledge development platform (Tremblay 2004). It has also been found that highly structured formal training programmes are not always the best way to assist people to learn and solve problems (Allen, Ure \& Evans 2003). This, then, requires organisations to seek alternative informal ways to share knowledge (Tang \& Yang 2005; Tremblay 2004). The sharing of knowledge results in VCoPs receiving considerable attention while searching for new ways to draw on expertise dispersed across global operations. This development impacts organisations, thereby enabling them to respond more speedily to the demands of their stakeholders. According to Van Winkelen (2003), the fast pace of change in business environments is an essential factor to contend with. Within this context, the use of VCoPs to enhance both tacit and explicit knowledge sharing among stakeholders is the central theme of this research. Tacit knowledge is what people carry in their minds and is, therefore, difficult to access (Hara \& Hew 2007; Panahi, Watson \& Partridge 2012). Explicit knowledge can be articulated, codified and stored (Hara \& Hew 2007; Panahi et al. 2012).

The difference between knowledge and information is that knowledge enables making a quick decision, whereas information provides direction to decision-making (Nissen 2002). Knowledge can be asserted as 'a fluid mix of framed experience, values, contextual information, expert insight, and grounded intuition that provides a framework for evaluating and incorporating new experiences and information' (Arntzen-Bechina \& Leguy 2007:154). This definition of knowledge implies that the tacit part of knowledge, such as processes, practices and norms, is incorporated 
by the individual. In this case, interpretation of particular knowledge can be viewed as subjective, depending on the beliefs, values, experiences and perception of an individual. From the above definition of knowledge, it can be inferred that information can be considered as a subset of knowledge.

\section{Literature review Knowledge sharing}

Knowledge sharing is the process of transferring knowledge from one entity to another (Noor \& Salim 2011). This transfer of knowledge can take place within individuals, groups and departments to accomplish a particular task (Noor \& Salim 2011). Furthermore, Noor and Salim (2011) find that the fundamental objective of sharing knowledge is to generate new ideas and develop new business opportunities in an enterprise. Kim and Park (2017) define knowledge sharing as the process of exchanging task information, expert knowledge and feedback regarding a procedure or product in order to create new knowledge or ideas, deal with issues and achieve common objectives. Kim and Park (2017) further state that knowledge sharing is considered to be an essential means through which employees make positive contributions to knowledge application and innovation among individual employees and teams (e.g. by increasing firm innovation capabilities and reducing production costs), ultimately leading to the sustainable development of the organisation. Furthermore, Zheng (2017) explains that knowledge sharing is an individual's conscious behaviour and decision to voluntarily externalise or transmit knowledge (codify, show, describe, etc.) and the capability of knowledge receivers to internalise or absorb knowledge (learn by doing, read, interpret, etc.). The results of such knowledge sharing are that knowledge is to be jointly owned by two or more parties.

Therefore, knowledge sharing, alternatively referred to as knowledge flow in this research, refers to the process of knowledge transmission from knowledge owners (such as an individual or a business unit in an organisation) to knowledge receivers. The shared knowledge eventually resides in both the knowledge owners and knowledge receivers. The shared knowledge eventually contributes to the innovativeness and sustainability of an organisation.

\section{Communities of practice}

A popular way to share common interests and practices is by using communities of practice (CoPs). Iaquinto, Ison and Faggian (2011) describe three characteristics central to the existence of CoPs. These characteristics are mutual engagement in a shared practice, the creation of a common repertoire and negotiation of a joint enterprise. Furthermore, CoPs are summarised as groups of people who share knowledge because of their common interest and practice (Agrifoglio 2015; Correia, Paulos \& Mesquita 2010). These common interests are driven by the desire and need to share problems, experiences, insights and best practices that affect all the relevant participants (Boateng 2011). CoPs also refer to groups of people having shared visions and compassion through continuous activities (Hu \& Kuo 2013). A similar idea is shared by Boh (2014), who describes a CoP as a group whose members regularly engage in sharing and learning from one another, based on their common interests. The above-mentioned views suggest that the similarity of the members in CoPs is determined by their common interest and shared identity that results in mutual objectives and practice.

\section{Virtual communities of practice}

A contrasting entity arises with VCoPs in relation to CoPs, when supported by information and communication technologies (ICTs), known as VCoPs. VCoPs are those members that use ICT as their primary mode of interaction (Correia et al. 2010). VCoPs are conceptualised as similar to CoPs, but their communication usually takes place via electronic means (Correia et al. 2010). Hu and Kuo (2013) further indicate that VCoPs are similar to CoPs, but information sharing in VCoPs takes place through the use of ICTs (Hu \& Kuo 2013). This concept is also supported by Boh (2014), who explains that ICTs take on a crucial role in supporting CoPs. It is then evident that VCoPs are the same concept as CoPs, but the difference lies in the use of the ICT component in VCoPs versus the face-to-face interaction used in CoPs.

Furthermore, VCoPs are required, especially in organisations facing the challenge of disseminating organisational knowledge, to reside in some individual experts (Ardichvili et al. 2006; Hu \& Kuo 2013). VCoPs are found to perform a central role in promoting collaboration between members who are dispersed by both time and space (Correia et al. 2010). Further, Tang and Yang (2005) suggest that VCoPs are viewed as an informal means to enhance knowledge sharing across time and distance. It is evident that in traditional CoPs, individuals often interact on a face-to-face basis, while VCoPs operate in multiple modes including both faceto-face meetings (when necessary) as well as using ICT (Kimball \& Ladd 2004). VCoPs can be a face-to-face meeting, a virtual group or a combination of both (Ford, Korjonen, Keswani, \& Hughes, 2015). This suggests that VCoPs may provide added value as they are ubiquitous, thus allowing participants to share their knowledge at any point in time, given that Internet technology and its connectivity exists.

An advantage of VCoPs is the ability to allow innovative ways of creating and sharing organisational knowledge (Allan \& Lewis 2006). Groups of experts in VCoPs function as an interdependent network, with the shared goal of developing their practice and doing their work better (Lavoue 2011). Ford et al. (2015) also suggest that VCoPs contribute to continuing professional development, improvement and innovation, as well as communication over geographical distances.

Knowledge managers mainly focus on formal processes of establishing explicit knowledge sharing approaches (Vuori \& Okkonen 2012). This calls for recognising VCoPs 
to share tacit knowledge, which is knowledge typically embedded in a specific context. According to (Ardichvili, Maurer, Wentling \& Stuedemann 2006), tacit knowledge has long been recognised as the most important element in sustaining the competitive advantage of organisations. This points to assumptions that virtual knowledge transfer enhances sharing of the tacit part of knowledge, while also capitalising on already-existing explicit knowledge (Panahi et al. 2012).

In summary, CoP and VCoP members experience different environments because of the media through which they primarily interact, and therefore they face dissimilar realities. For instance, the different time zones and geographic separation between members in CoPs urge them to resort to technologies although they are not, in real terms, substitutes for face-to-face interactions (Wenger, McDermott \& Snyder 2002). Boh (2014) also mentions that often much modern work interaction occurs virtually between individuals located in disparate geographical areas who may never meet face-to-face, and subsequently ICT takes on a crucial role in supporting knowledge sharing in CoPs. This development suggests the need for VCoPs as methods to support and enhance knowledge sharing among experts dispersed in various geographical areas.

\section{Recent research on knowledge sharing within virtual communities of practice}

The literature summarises the following five findings:

- 'Cooperative learning environments: Virtual communities of practice in the healthcare sector' by Saigi-Rubio and Gonzalez-Gonzalez (2014): The research focusses on the role of knowledge sharing and the benefits provided by $\mathrm{VCoP}$ in the healthcare sector. The research thus aims at examining the benefits of VCoP to professionals in the healthcare field. The discussion in the research indicates how the members of a community carry out their professional activities at both management and performance levels. The set of benefits from the use of VCoP - at personal, community and organisational levels - was also revealed.

- 'Role of The role of virtual communities of practice in knowledge management using web 2.0' by Al-ghamdi and Al-ghamdi (2015): this research is a discussion of the critical importance of knowledge management (KM) in helping organisations to improve performance and achieve the desired goals. The focus of the research is on the obstacles to the application of KM, most prominent of which are the difficulty of tacit KM, the poor cooperation and sharing in KM, and the difficulty of dealing with KM techniques. This research aims to determine how to take advantage of the VCoPs that employ Web 2.0 technologies to overcome these obstacles. A discussion is presented on how Web 2.0-based CoP plays major roles in capturing tacit knowledge, facilitating innovation, as well as knowledge sharing and collaboration. However, no model or approach is mentioned to enable the optimisation of knowledge sharing within VCoPs.
- 'Research on knowledge sharing in communities of practice in international development' by Cummings (2015) focuses on the role of CoP in its ability to link actors from many different organisations and different constituencies. Online communities are able to link people and organisations across continents. The research discusses the experience of CoPs in the development sector. These experiences will be relevant to other nondevelopment activities, which may be less organisation bound, such as the health sector and academia. There is no mention of any model surrounding the optimisation of knowledge sharing within VCoPs.

- 'Research on knowledge sharing in virtual distributed environments: main motivators, discrepancies of findings and suggestions for future research' by Chen and Hew (2015): this research reviews some previous empirical research that identifies the main theories and factors used to explain online knowledge sharing. The findings suggest that the incentive items of knowledge sharing could be grouped into three main categories: personal, social factors and organisational factors. Of these factors, trust is the most widely discussed. Further, this research focusses on several main discrepancies among past research studies, such as the notion of perceived compatibility, norm of reciprocity and trust to provide possible directions for future studies. Discrepancies that exist in the behaviour and intention of knowledge sharing are discussed. For example, a number of studies indicate trust as a positive factor that motivates knowledge sharing intention, which results in the contribution to the actual knowledge sharing behaviour. At the same time, the research discusses other studies suggesting that the influence of trust in knowledge sharing behaviour is not significant. There is no mention of any model or approach to knowledge optimisation in VCoPs.

- 'Research on knowledge sharing in communities of practice: Examining usefulness of knowledge from discussion forums versus repositories' by Boh (2014): this research takes on the role that ICTs play in supporting knowledge sharing in VCoPs. It examines the use of two key types of ICTs - knowledge repositories and online discussion forums. Two event-driven questionnaires were conducted with members of a CoP in a consulting firm to test a hypothesis. The hypothesis is about how various factors would differ in their influence on knowledge sourcing from knowledge repositories and online discussion forums. There is little empirical research comparing how different types of ICTs are effectively utilised for knowledge sharing. Much of the KM literature has focussed on supply-side arguments for both knowledge repositories and discussion forums. There is; however, increasing recognition that it is also important to examine the demand side - examining what facilitates knowledge seeking. This research adds to demand-side knowledge seeking. It focusses on the demand for knowledge in CoPs by examining how CoP members source and reuse knowledge from others through knowledge repositories and online discussion forums. This particularly examines the purposeful use of both knowledge repositories and 
online discussion forums in CoPs as alternative knowledge sources when individuals conducting knowledge work are looking for specific types of knowledge to solve a problem on hand.

Therefore, literature published between 2012 and 2016 indicates there are no research results available that have a focus on scientific models or approaches that may enable the optimisation of knowledge sharing within VCoPs. This compelled the authors to explore and find relevance in conducting research to investigate the existence of a scientific model or approach that enables the optimisation of knowledge sharing within VCoPs.

\section{Problem statement}

The research problem reads: 'enterprises do not have a formalised approach to successfully utilise knowledge sharing'. The question is, therefore: what scientific approach or model can be used to particularly optimise knowledge sharing in an enterprise?

In order to address the above problem statement, three investigative questions are presented:

- How have VCoPs evolved contributing to knowledge sharing?

- How are current processes or models applied to knowledge sharing in enterprises?

- How would a scientifically-based model be applied to particularly enhance knowledge sharing within VCoPs?

\section{Research methodology Research design}

The outflow of the research design recommended by Warden (2010) and Babbie (2004) results in the following research design adopted in this research.

Firstly, the review of literature identifying the research problem clearly and the ensuing research questions and investigative subquestions are discussed. Secondly, current literature is used to define the main concepts in this research, for example, the definition and concepts of virtual communities, VCoPs, social networks and knowledge sharing. Thirdly, the relevant research methods to address the research problem are discussed. Fourthly, the findings are established through a review of literature and empirical research. A current scientifically-based approach or model for utilising knowledge sharing in an enterprise is identified through the review of literature, and then empirical testing of the theoretical approaches or models was conducted on the relevant VCoPs. Some concepts were also generated from the empirical research. Fifthly, analysis of the findings was conducted based on the data collected from empirical research, by triangulating the data found through empirical research compared to the proposed theoretical models explored in the literature. Thus, concluding remarks are drawn after the analysis; some recommendations and a conclusion are then made.

\section{Research paradigm}

The epistemological orientation of this research is interpretivist. The intention in this research is to describe, explain and interpret the findings in the context of knowledge sharing in VCoPs. The idea of an exploratory and explanatory approach is supported by Duane, Thomas, Cornell and Hilton (2014), who suggest that scientific knowledge is found not only in abstracting and generalising but also can be derived from a deep and full explanation and interpretation of the context. Thus, the discussion and analysis in this research represent the responses given by the participants within their context in their respective VCoPs and were not selected and distorted by the researcher.

The ontological assumption in this research is that the emphasis is placed on the participants' involvement in the development of knowledge within VCoPs and based on their subjective interpretation of the reality of knowledge sharing in their respective VCoPs. The concepts of knowledge optimisation within VCoPs are revealed in the data the participants provided in the questionnaires. Their responses were then interpreted by the researcher to conduct the final analysis and draw conclusions.

Therefore, two questionnaires were utilised to obtain qualitative responses from the research participants. Further, an explanatory research method was applied to analyse data and concepts obtained from both literature and the questionnaires, mainly through inductive reasoning approaches. In explaining the data obtained from the respondents, a phenomenological approach was followed broadly through qualitative interpretivist methods of analysis. Thus, the interpretation, discussion and analysis in this research represent the responses given by the participants so that bias that might emanate from the literature as well as the researcher might be avoided.

\section{Research approach}

No single research approach is deemed suitable with regard to knowledge sharing. Therefore, a combination of research methods was utilised in this research. Firstly, a review of literature was conducted to define concepts to establish current scientific-based models that may have the potential to enhance knowledge sharing in an enterprise. This was followed by administering the first questionnaire in 2011-2012 for the empirical research. Finally, a second questionnaire was administered in 2016 to confirm the validity of the proposed model of knowledge sharing that emerged from the initial findings. In brief, all investigative questions were dealt with using relevant approaches applicable to solve them.

The first investigative question formulated reads: how have VCoPs evolved contributing to knowledge sharing?

In this case, a review of literature was applicable to explore and explain the evolution of VCoPs and their contribution in knowledge sharing. 
The assumption in this research is that there may be scientifically-based theoretical models that are available but not necessarily utilised in enterprises. The researcher is of the opinion that scientifically-based models can be established from the review of literature. However, literature review may or may not necessarily influence how the topic is looked at, thereby preventing the development of some new way, as suggested by Punch (2005). This suggests that literature in this research enables the researcher to identify scientifically-based models that may potentially enhance knowledge sharing in an enterprise. As Babbie (2004) suggests, every research report should be placed in the context of the general body of scientific knowledge and bring the reader up to date with previous research in the area. Therefore, models that can particularly enhance knowledge sharing in VCoPs were explored and explained based on current literature.

The second investigative question is as follows: how are current models applied to knowledge sharing in an enterprise?

The first author (main researcher) had limited prior knowledge of professional practice of VCoPs to define the current models applied to knowledge sharing in an enterprise. The researcher was, therefore, compelled to investigate contemporary scientifically-based models and subsequently to investigate how they would be applied to particularly optimise knowledge sharing within VCoPs. A literature review was suitable in exploring and explaining such scientifically-based theoretical models.

A qualitative research approach was utilised to deal with the third investigative question, which reads: how would a scientifically-based model be applied to particularly enhance knowledge sharing within VCoPs? The indispensable condition for a qualitative approach is a commitment to perceiving the world from the point of view of the participants (Brynard, Hanekom \& Brynard 2014). Bryman (2004) also concurs that a qualitative approach enables a researcher to describe and analyse the experiences of humans and their groups from the point of view of those being studied. The emphasis on qualitative research is, according to Bryman (2004), on the phenomenological approach, in which the researcher grasps the meanings of a person's activities from that person's point of view. Therefore, two questionnaires were utilised to obtain the participants' point of view with regard to optimisation of knowledge sharing in VCoPs.

\section{Research strategy}

\section{Selection of participants}

VCoPs selected for this research were the Gurteen Knowledge Community, KM4dev, KM Practitioners Group, AIIM Network for Intelligent Information Management, Knowledge Management Education (KMedu) Hub and actKM. These VCoPs were drawn from a global VCoPs directory.

The Gurteen Knowledge Community is a global learning community for people who are committed to making a difference: people who wish to share and learn from each other and who strive to see the world differently, think differently and act differently. Knowledge Management for Development (KM4Dev) is a community of international development practitioners who are interested in KM and knowledge-sharing issues and approaches and who seek to share ideas and experiences in this domain. KM Practitioners Group aim to share knowledge and experience of how practical knowledge sharing and management can be successful in organisations. AIIM (Intelligent Information Management) group aim to help users, project managers and business executives become more savvy information managers, strategists and technology buyers. The actKM Forum is a non-profit learning community dedicated to building and sharing knowledge about public sector $\mathrm{KM}$ and contributing to improved public sector performance through effective management of knowledge and information resources. The KMedu Hub is an independent source and unique place to find, discuss and promote $\mathrm{KM}$ education and training worldwide.

The moderators of the prospective VCoPs and the relevant VCoP groups on LinkedIn and Twitter were approached. The researcher emailed a brief explaining the purpose of the research and received a sizeable buy-in from the moderators for their individual members to participate in this research. Neuman (2006), for example, supports the use of key members to reach individual members, as it is difficult to reach all members in online communities.

Individual members were also approached to recommend other members to participate. This was done in two ways. Firstly, an electronic request was posted on the VCoPs' websites. The same request was also posted on the relevant VCoP groups on LinkedIn and Twitter, as they extend their discussions on these two social networks. Secondly, the e-mail addresses of all individual participants were acquired from their respective moderators and VCoP personal profiles. This enabled the researcher to make direct contact with the individual members to request their participation in this research.

In addition, a snowball sampling technique was utilised to obtain individual participants. Snowball sampling is a technique whereby selected participants refer to other directly or indirectly related participants (Neuman 2006). In brief, the research participants were asked to refer to other VCoP members to partake in the questionnaire. In the first questionnaire, 60 participants submitted their responses across five VCoPs. In the second questionnaire, a maximum of 60 responses were expected. However, the researcher ceased receiving responses after 41 participants completed the questionnaire. The decision to stop receiving responses was made after a saturation level was reached, when similar and redundant responses were being received.

\section{Data collection}

There were two basic strategies utilised in this research a review of the literature and administration of online 
questionnaires. As stated in the 'problem statement' section, there were three investigative questions:

- How have VCoPs evolved contributing to knowledge sharing?

- How are current processes or models applied to knowledge sharing in enterprises?

- How would a scientifically-based model be applied to particularly enhance knowledge sharing within VCoPs?

The data for the first two investigative questions were acquired from the literature review. The data for the third investigative question were collected through an online questionnaire (also called a Web-based questionnaire). Data were collected in two phases and over two periods - the first phase was in 2011-2012 and the second phase in 2016. The intention of the first phase was to test the applicability of the proposed knowledge-flow model in optimising knowledge sharing within VCoPs. In the second phase, a questionnaire was deployed to confirm the current applicability of the model in optimising knowledge sharing in the contemporary VCoPs.

\section{Data analysis}

Various analysis methods were deployed in this research. One was the use of an analytic induction method of analysis. The responses received to both questionnaires were analysed to establish some premises derived from the data. The premises aided in reaching final conclusions and recommendations. The other method was to use the Miles and Huberman framework for qualitative analysis (Punch 2005). This framework for analysis includes data reduction, data display and drawing and verifying conclusions. Data reduction and display rest mainly on the operations of coding and memoing. In terms of coding, descriptive and inferential coding analysis methods were utilised in this research. That is, the responses were initially described as they appeared in the questionnaires and a piece of data (label) was assigned to them. Then, each of the similar data points attached to a certain concept or label were interpreted and summarised, which is typical of inferential coding analysis. Further, memoing enabled the researcher to make a profound interpretation of the summarised data, by questioning the new patterns that were achieved through the coding methods of analysis.

\section{Ethical considerations}

In this research, the moderators and all other participants of each of the potential VCoPs were approached to obtain their consent to participate, explain the purpose of this research and gain access to key contact information.

\section{Measures for trustworthiness}

The concept of using multiple sources of evidence to increase validity is recommended by Yin (2003) and suggests that various literature sources be used to authenticate the validity of theoretical findings. Data were triangulated with data obtained from the literature in order to provide a scientific-based explanation to the data given by the participants. Multiple sources of evidence were used to validate the various information collected from the literature. Various literature sources, such as journal articles, books and websites, were used to authenticate the theories established from the literature review.

In addition, questionnaire two (conducted in 2016) was utilised to confirm the applicability of the extended life cycle knowledge flow model, which was tested in questionnaire one (conducted in 2011-2012), to existing knowledge sharing within VCoPs.

The same VCoPs were used with the intention that the same or very similar respondents would participate in the followup questionnaire conducted in 2016. The intention was to maintain, as far as possible, the reliability of this research. Bernard (2013) suggests the replication of a study should yield more or less the same results each time you use it on the same or similar participants. Thus, a second questionnaire administered to the VCoP participants aimed to confirm the current applicability of the extended life cycle knowledge flow model. This would result in comparing and verifying the validity and reliability of the data collected in 2011-2012 to that of the 2016 questionnaire responses.

\section{Data protection}

In terms of data protection, only the researcher has access to the data set, as a username and password are required to view the responses. Thus, the data is protected.

\section{Results}

The answers to the investigative questions are summarised in the following subsections.

\section{How have virtual communities of practice evolved contributing to knowledge sharing?}

The objective of this investigative question was to analyse and compare various definitions and concepts of VCoPs and their contribution to knowledge sharing. A literature review was conducted to establish the historical evolution of VCoPs, theoretical concepts of VCoPs and their contribution in enhancing knowledge sharing. The review resulted in the need to identify and develop scientifically-based models that could potentially enhance knowledge sharing in an enterprise.

The central notion of VCoPs is to acquire knowledge, which a newcomer learns from the established members of a particular VCoP. The concept of VCoP is the assumption that less-experienced members of a community can learn in social interactions from experienced experts of a specific knowledge domain (Lave \& Wenger 1991). Other crucial advantages of VCoPs are their ability to promote informal knowledge sharing. Informal knowledge networks help to overcome knowledge flow barriers and stimulate the sharing of tacit knowledge. 


\section{How are current processes or models applied to knowledge sharing in enterprises?}

The objective of this investigative question was to identify current scientific processes or models applied to knowledge sharing in enterprises. After a thorough investigation of the literature, the life cycle knowledge flow model (Nissen 2014; Nissen \& Levitt 2002) was established as comprehensive to be able to establish as the basis to conduct empirical research to enhance knowledge sharing within VCoPs. The phases in the life cycle knowledge flow model include creation, organisation, formalisation, distribution, application and evolution (Nissen 2014; Nissen \& Levitt 2002).

From the literature, it was established that the life cycle knowledge flow model (Nissen 2014; Nissen \& Levitt 2002) had not been applied or adapted to the optimisation of knowledge sharing within VCoPs. However, the model was taken as the basis to conduct questionnaires and to investigate its adaptability and applicability to knowledge sharing within VCoPs. Thus, the researcher needed to answer the third investigative question, in an effort to establish the application of the model to enable the optimisation of knowledge sharing in VCoPs.

\section{How would a scientifically-based model be applied to particularly enhance knowledge sharing within virtual communities of practice?}

The objective of this investigative question was to investigate if the life cycle knowledge flow model (Nissen 2014; Nissen \& Levitt 2002) could be applied to particularly enhance knowledge sharing within VCoPs. As mentioned before, questionnaire one and questionnaire two were conducted in 2011-2012 and 2016, respectively, to obtain responses from participants of VCoPs. This investigative question enabled the researcher to answer the main research question, briefly discussed in the following.

\section{Answering the main research question}

The main research question reads: what scientific approach can be used to optimise knowledge sharing within VCoPs?

The life cycle knowledge flow model exists in the literature, but it was not designed or applied to knowledge sharing optimisation within VCoPs. An extended life cycle knowledge flow model was thus established to enhance knowledge sharing within VCoPs. This extended model covers six phases of knowledge development to particularly optimise knowledge sharing within VCoPs. Thus, this research is vital in revealing the extended model of knowledge flow that can be used and adapted in VCoPs. The outflow of such a model is to enhance knowledge sharing within VCoPs and in turn to develop and optimise knowledge sharing in an enterprise. The first phase enhances the creation of both tacit and explicit knowledge. The second phase optimises the organisation of knowledge. The third phase enhances the formalisation of tacit knowledge. The fourth phase optimises the distribution of knowledge. The fifth phase optimises the application of knowledge. The sixth phase enhances the evolution of knowledge.

\section{Discussion}

The first objective of this research was to investigate the historical evolution of VCoPs, theoretical concepts of VCoPs and their contribution in enhancing knowledge sharing. The central notion of VCoPs is to acquire knowledge, which a newcomer learns from the established members of a particular VCoP. The concept of VCoPs is the assumption that lessexperienced members of a community can learn in social interactions from experienced experts of a specific knowledge domain. Other crucial advantages of VCoPs are their ability to promote informal knowledge sharing. Informal knowledge networks help to overcome knowledge flow barriers and stimulate the sharing of tacit knowledge.

The second objective of this study is to identify current scientific processes or models applied to knowledge sharing in enterprises. After a thorough investigation of the literature, the life cycle knowledge flow model was established as comprehensive to be able to establish as the basis to conduct empirical research to enhance knowledge sharing within VCoPs. The phases in the life cycle knowledge flow model include creation, organisation, formalisation, distribution, application and evolution.

From the literature, it was established that the life cycle knowledge flow model had not been applied in or adapted to the optimisation of knowledge sharing within VCoPs. Thus, the researcher was compelled to answer the third investigative question, in an effort to establish the application of the model to enable the optimisation of knowledge sharing in VCoPs.

The third objective of this study was, then, to investigate if the life cycle knowledge flow model could be applied to particularly enhance knowledge sharing within VCoPs. Questionnaires one and two were conducted in 2011-2012 and 2016, respectively, to get a response from the actual participants of VCoPs.

The responses from the questionnaire provided the researcher the category of tacit and explicit knowledge that is created by VCoPs, which is missing in the current literature. For example, the types of knowledge created in VCoPs were established as original ideas, research results, opinions, replies to other opinions, comments on academic articles and forwarding other research articles to members. The types of content that are created by VCoPs were also established from the questionnaire responses. These included work-related information, life-oriented information, research results, developments in academic activities and other various aspects of knowledge.

The extended model also enhances the organisation of knowledge in VCoPs. The responses in both questionnaires provided new insights into how knowledge is organised (for example, author name, date, topic, subject area, etc.) and 
retrieved (search by author, web archives, keyword, e-mails, links, etc.) in VCoPs.

The extended model also optimises the formalisation of tacit knowledge sharing in VCoPs. This results in enhancing tacit knowledge sharing and makes information easily accessible and understandable to users. The extended life cycle knowledge flow model revealed that knowledge in VCoPs can be communicated through different forms, such as storytelling, diagrams, video clips, text, pictures and illustrations.

The extended life cycle knowledge flow model also enables optimisation of knowledge distribution within VCoPs. The respondents indicated that the audience to whom you distribute your knowledge is contextual depending on the nature of the content and the audience. For example, some content may be work related, which you distribute to colleagues, other content may be on topics of common interest, which you can share with interest groups, and other content may be general issues that may be distributed and intended to reach everyone.

The extended life cycle knowledge flow model also enables the optimisation of the application of knowledge sharing. The responses to both questionnaires revealed that knowledge shared within VCoPs can be utilised to develop common standards, upgrade individual knowledge and promote lifelong learning.

The extended life cycle knowledge flow model also enables the optimisation of the evolution of knowledge in VCoPs. This results in enabling individual members as well as organisations to revive and upgrade their existing knowledge.

Therefore, the extended life cycle knowledge flow model can be utilised as the basis to develop criteria that will enable to enhance knowledge sharing within VCoPs. VCoPs can measure their knowledge sharing expectations and effectiveness against the six phases of the extended model.

\section{Conclusion}

The optimisation of information and knowledge sharing in organisations is crucial in enhancing work flow and attending to customer needs more speedily and effectively. Within this context, the use of VCoPs to optimise both tacit and explicit knowledge sharing within stakeholders is the central theme of this research.

The participants in this research were drawn from VCoPs that have membership presence worldwide. In addition, their knowledge was extensively shared in an open-ended questionnaire and, therefore, their views and expertise can be generalised to all VCoPs that aim to share information and knowledge in various fields. This is justified as their sound knowledge of VCoPs, knowledge and knowledge sharing as well as the diverse backgrounds of the participants are well established.
The main research problem reads: enterprises do not have a formalised approach to successfully utilise knowledge sharing. Three investigative questions were presented to address the problem. The first investigative question was: how have VCoPs evolved contributing to knowledge sharing? The objective of this investigative question was to analyse and compare various definitions and concepts of VCoPs and their contribution to knowledge sharing. A literature review was conducted to establish the historical evolution of VCoPs, theoretical concepts of VCoPs and their contribution in enhancing knowledge sharing. The review resulted in the need to identify and develop scientifically-based models that could potentially enhance knowledge sharing in an enterprise.

The central notion of VCoPs is to acquire knowledge, which a newcomer learns from the established members of a particular VCoP. The concept of VCoPs is the assumption that lessexperienced members of a community can learn in social interactions from experienced experts of a specific knowledge domain. Another crucial advantage of VCoPs is their ability to promote informal knowledge sharing. Informal knowledge networks help to overcome knowledge flow barriers and stimulate the sharing of tacit knowledge.

However, there are challenges in VCoPs in terms of knowledge sharing. These include forcing members to participate in VCoPs, which results in hindering knowledge sharing. The second challenge emerges as the result of resistance to change, such as disallowing outside membership and/or resistance by existing members. The third challenge is because of a lack of measurable outcomes that could have resulted from knowledge sharing in VCoPs.

Barriers in knowledge sharing can significantly hamper firm performance, as organisations may be unable to tap into the know-how and expertise of their employees. For example, some companies such as International Business Machines (IBM), Shell, the World Bank, The United Nations Development Programme (UNDP), Food and Agriculture Organization (FAO) and Siemens deliberately support their VCoPs in order to enhance the sharing of tacit and explicit knowledge. The concept of CoPs stems from the need to create a new mode of learning and is viewed as a specific form of knowledge development. In this context, ICT infrastructures are critical in enabling the flow of knowledge. This prompted the development of VCoPs. In view of the above benefits, challenges and barriers, the identification and development of scientifically-based models that can potentially enhance knowledge sharing in an enterprise was found crucial in this research.

The second investigative question was, then: how are current processes or models applied to knowledge sharing in enterprises? The objective of this investigative question was to identify current scientific processes or models applied to knowledge sharing in enterprises. The researcher had limited prior knowledge and was not closely linked to professional practice of VCoPs to enable him to determine the current models applied to knowledge sharing in enterprises. 
The researcher was compelled to investigate contemporary scientifically-based knowledge flow models in an enterprise and subsequently how they would be applied to particularly enhance knowledge sharing within VCoPs. A literature review was deemed suitable in exploring such scientificallybased theoretical models.

After a thorough investigation of the literature, the life cycle knowledge flow model was established as comprehensive to be able to establish as the basis to conduct empirical research to enhance knowledge sharing within VCoPs. The phases in the life cycle knowledge flow model include creation, organisation, formalisation, distribution, application and evolution.

Thus, the third investigative question was: how would a scientifically-based model be applied to particularly enhance knowledge sharing within VCoPs? The objective of this investigative question was to investigate if the life cycle knowledge flow model could be applied to particularly enhance knowledge sharing within VCoPs. Questionnaires 1 and 2 were conducted in 2011-2012 and 2016, respectively, to get a response from the actual participants of VCoPs.

A qualitative methodology was utilised to deal with the third investigative question. The use of a qualitative approach enabled the researcher to describe and analyse the experiences of the participants from their point of view. The use of qualitative inquiry in this research is also justified as it allows the participants to provide a more open-ended way of giving their views. Thus, the assertion in qualitative research enabled the researcher to emphasise an inductive approach, which placed emphasis on the generation of theories or models based on the responses given in both of the questionnaires conducted.

The responses from the questionnaire provided the category of tacit and explicit knowledge that is created by VCoPs, which was missing in the current literature. For example, the types of knowledge created in VCoPs were established as original ideas, research results, opinions, replies to other opinions, comments on academic articles and forwarding other research articles to members.

The extended model also enhances the organisation of knowledge in VCoPs. The responses in both questionnaires provided new insights into how knowledge is organised (for example, author name, date, topic, subject area, etc.) and retrieved (search by author, web archives, keyword, e-mails, links, etc.) in VCoPs. Thus, the extended life cycle knowledge flow model enhances the organisation of knowledge in VCoPs.

The extended model also optimises the formalisation of tacit knowledge sharing in VCoPs. This results in enhancing tacit knowledge sharing and making content easily accessible and understandable to users. The extended life cycle knowledge flow model reveals that knowledge in VCoPs can be communicated through different forms such as storytelling, diagrams, video clips, text, pictures and illustrations. Various formats are also used to make tacit knowledge visible and understandable to others, such as by using PowerPoint presentations, blogs, hyperlinks and by using different languages suitable to individuals. This is a clear indication that the extended life cycle knowledge flow model enables the enhancement of the formalisation of knowledge in VCoPs.

The extended life cycle knowledge flow model also enables the optimisation of knowledge distribution within VCoPs. The respondents showed that the audience to whom you distribute your knowledge is contextual depending on the nature of the content and the audience. For example, some content may be work related, which you distribute to colleagues, other content may be on topics of common interest, which you can share to interest groups, and other content may be general issues that may be distributed and intended to reach to everyone. In addition, social context, cultural values and the knowledge sources as well as the knowledge receiver's desire to share and learn, respectively, are determinant factors in the context of knowledge distribution within VCoPs. The importance of the extended life cycle knowledge flow model in optimising the distribution of knowledge within VCoPs is documented in this research.

The extended life cycle knowledge flow model also enables the optimisation of the application of knowledge sharing. The responses to both of the questionnaires conducted revealed that knowledge shared within VCoPs can be utilised to develop common standards, upgrade individual knowledge and promote lifelong learning. VCoPs also enhance tacit and explicit knowledge that can be applied in solving individual as well as organisational problems.

The extended life cycle knowledge flow model also enables the optimisation of the evolution of knowledge in VCoPs. This results in enabling individual members as well as organisations to revive and upgrade their existing knowledge. Both individuals and organisations use VCoPs to generate new experiences and perspectives, adapt to new practices, fill knowledge gaps and avoid redundancy, contribute to community benefits and enable individuals to upgrade their individual knowledge. This is a clear indication of the extended life cycle knowledge flow model enabling the use of VCoPs in reviving and upgrading new knowledge on continual basis.

Therefore, the extended life cycle knowledge flow model can be utilised as the basis to develop a criteria that will enable enhancement of knowledge sharing within VCoPs. VCoPs can measure their knowledge sharing expectations and effectiveness against the essentials of the extended model.

\section{Recommendations}

The findings of this research show that the extended life cycle knowledge flow model optimises knowledge creation, organisation, formalisation, distribution, application and evolution within VCoPs. Thus, the extended model can be adapted to qualitatively analyse and interpret the effective utilisation of VCoPs in knowledge sharing. The extended model can be used by moderators and individual participants 
of VCoPs as well as organisations that have introduced VCoPs, to analyse and establish VCoPs' knowledge sharing capability in light of the six phases of the extended life cycle knowledge flow model.

For example, in terms of knowledge creation, the content of tacit and explicit knowledge sharing can be analysed in order to establish whether they are work-related, life-oriented, research results or a combination of other knowledge content. The role players in knowledge creation can also be examined to determine whether they are contributing or merely consuming, facilitating or moderating messages.

In terms of knowledge organisation, criteria can be developed to check both the organisation and retrieval of knowledge within VCoPs for example, if the knowledge is organised by author name, date, topic, subject area, chronological order, mind mapping or per keyword. The knowledge retrieval can also be checked in terms of date, author, topic, e-mail trails, through archives, keywords or a combination of two or more of these features.

The formalisation of tacit knowledge is another feature that can be analysed through the use of the extended model. The formalisation of such knowledge can be measured if it is made explicit to others by using case studies, storytelling, diagrams, video clips, text, pictures, illustrations, PowerPoint presentations, blog posts, reference hyperlinks, question and answer comments, as well as multilingual approaches.

The optimisation of knowledge distribution within VCoPs can also be established through the use of the extended model. The content distributed to individuals can be checked to determine whether it is task-related, topics of common interest or general issues. At the same time, people who receive the content can be checked to ascertain whether they are selected groups, core groups or all members. In brief, the enhancement of content distribution can be determined with the help of the model.

The extended model also enables the optimisation of the application of knowledge sharing. The questionnaire responses revealed that knowledge shared within VCoPs can be utilised to develop common standards, upgrade individual knowledge and promote lifelong learning. VCoPs also enhance tacit and explicit knowledge to apply in solving individual as well as organisational problems. Therefore, the application of knowledge within a particular VCoP can be established based on the model.

The extended model also enables VCoPs to optimise the evolution or continuous development of knowledge. This results in enabling individual members as well as organisations to revive and upgrade their existing knowledge on continuous basis. Both individuals and organisations use VCoPs to generate new experiences and perspectives, adapt to new practices, fill knowledge gaps and avoid redundancy, contribute to community benefits and enable individuals to upgrade their individual knowledge. The optimisation of generating new knowledge can be measured by the model.

\section{Acknowledgements}

The financial assistance of the National Research Foundation towards this research is greatly acknowledged.

\section{Competing interests}

The authors declare that they have no financial or personal relationships that may have inappropriately influenced them in writing this article.

\section{Authors' contributions}

H.O. conducted this research in fulfilment of a doctoral thesis. S.W. is the doctoral supervisor for this research and contributing author of this article.

\section{References}

Agrifoglio, R., 2015, Knowledge preservation through Community of Practice, Springer, Berlin.

Allan, B. \& Lewis, D., 2006, 'Virtual learning communities as a vehicle for workforce development: A case study', The Journal of Workplace Learning 18(6), 367-383. https://doi.org/10.1108/13665620610682099

Allen, S., Ure, D. \& Evans, S., 2003, Virtual communities of practice as learning networks, Brigham Young University Instructional Psychology and Technology, Utah.

Al-ghamdi, H.A.K. \& Al-ghamdi, A.A.K., 2015, 'The role of virtual communities of practice in knowledge management using Web 2.0', Procedia Computer Science 65, 406-411. https://doi.org/10.1016/j.procs.2015.09.102

Ardichvili, A., Maurer, M., Li, W., Wentling, T. \& Stuedemann, R., 2006, 'Cultural influences on knowledge sharing through online communities of practice', Journa of Knowledge Management 10(1), 94-107. https://doi.org/10.1108/136732 70610650139

Arntzen-Bechina, A.A. \& Leguy, C.A.D., 2007, 'An insight into knowledge flow in biomedical engineering science', The Electronic Journal of Knowledge Management 5(2), 153-160.

Babbie, E., 2004, The practice of social research, 10th edn., Wadsworth, Belmont, CA.

Bernard, H.R., 2013. Social research method: qualitative \& quantitative approaches. 2nd ed. Sage Publications: Los Angeles.

Boateng, W., 2011, 'Communities of practice as conduit for knowledge management: A sociological analysis of the macro level health care decision-making in Canada', International Journal of Humanities and Social Science 1(14), 29-36.

Boh, W.F., 2014, 'Knowledge sharing in communities of practice: Examining usefulness of knowledge from discussion forums versus repositories', The Data Base for Advances in Information Systems 45(2), 8-31. https://doi.org/10.1145/ 2621906.2621908

Bryman, A., 2004, Social research methods, Oxford University Press, Oxford, UK.

Brynard, D.J., Hanekom, S.X. \& Brynard, P.A., 2014, Introduction to research, 3rd edn., Van Schaik Publishers, Pretoria.

Chen, Y. \& Hew, K.F., 2015, 'Knowledge sharing in virtual distributed environments: Main motivators, discrepancies of findings and suggestions for future research', International Journal of Information and Education Technology 5(6), 466-471. International Journal of Information and
https://doi.org/10.7763/IIIET.2015.V5.551

Correia, A.M.R., Paulos, A. \& Mesquita, A., 2010, 'Virtual communities of practice: Investigating motivations and constraints in the processes of knowledge creation and transfer', Electronic Journal of knowledge Management 8(1), 11-20.

Cummings, S., 2015, 'Knowledge sharing in communities of practice in international development', viewed 10 June 2015, from https://knowledgeecologists. files.wordpress.com/2014/05/communities-of-practice-in-internationaldevelopmentfinal1.pdf

Duane, R.M., Thomas, J.S., Cornell, R.D. \& Hilton, T.P., 2014, Applied social research A tool for the human services, 9th edn., Cole Cengage Learning, Brooks, CA.

Ford, J., Korjonen, H., Keswani, A. \& Hughes, E., 2015, 'Virtual communities of practice: Can they support the prevention agenda in public health?', Online Journal of Public Health Informatics, viewed 01 July 2015, from http://ojphi.org

Hara, N. \& Hew, K.F., 2007, 'Knowledge-sharing in an online community of health-care professionals', Information Technology \& People 20(3), 235-261. https://doi.org/ 10.1108/09593840710822859

Hu, L. \& Kuo, T., 2013, 'How system quality and incentive affect knowledge sharing', Industrial Management \& Data Systems 113(7), 1048-1063. https://doi.org/ 10.1108/IMDS-01-2013-0015 
laquinto, B., Ison, R. \& Faggian, R., 2011, 'Creating communities of practice: Scoping purposeful design', Journal of Knowledge Management 15(1), 4-21. https://doi. purposeful design', Journal of Know

Kim, W. \& Park, J., 2017, 'Examining structural relationships between work engagement, organizational procedural justice, knowledge sharing, and innovative work behavior for sustainable organizations', Sustainability 9(2), 205. https://doi.org/ 10.3390/su9020205

Kimball, L. \& Ladd, A., 2004, 'Facilitator toolkit for building and sustaining virtua communities of practice', in P. Hildreth \& C. Kimble (eds.), Knowledge networks: Innovation through communities of practice, pp. 202-215, Idea Group Publishing, London.

Lave, J. \& Wenger, E., 1991, Situated learning: Legitimate peripheral participation Cambridge University Press, Cambridge, UK.

Lavoue, E., 2011, 'A knowledge management system and social networking service to connect communities of practice', in A. Fred, J.L.G. Dietz, K. Liu \& J. Filipe (eds.) Knowledge discovery, knowledge engineering and knowledge management (vol. 128 , pp. 320-322), Communications in Computer and Information Science, Springer, Berlin, Heidelberg.

Neuman, W.L., 2006, Social research methods: Qualitative and quantitative approaches, 6th edn., Pearson International Edition, Milwaukee, WI.

Nissen, E.M., 2002, 'An extended model of knowledge-flow dynamics', Communication of the Association for Information Systems 8, 251-266.

Nissen, M.E., 2014, Harnessing dynamic knowledge principles in the technologydriven world, ICG Global, Hershey, PA.

Nissen, M.E. \& Levitt, R., 2002, 'Dynamic models of knowledge flow dynamics', Working Paper No. 76, Center for Integrated Facility Engineering, Stanford University, Palo Alto, CA.

Noor, N.M. \& Salim, J., 2011, 'Factors influencing knowledge sharing capabilities in electronic government agencies in Malaysia', International Journal of Computer Science 8(4), 106-114.
Panahi, S., Watson, J. \& Partridge, H., 2012, 'Social media and tacit knowledge sharing: Developing a conceptual model', World Academy of Science, Engineering and Technology 64, 1095-1102.

Punch, K.F., 2005, Introduction to social research: Quantitative and qualitative approaches, 2nd edn., Sage, Los Angeles, CA.

Saigi-Rubio, F. \& Gonzalez-Gonzalez, I., 2014, 'Cooperative learning environments: Virtual communities of practice in the healthcare sector', eLC Research Paper Series 9, 15-26.

Tang, J. \& Yang, L., 2005, 'User role and perception of requirements in a web-based community of practice', Online Information Review 29(5), 499-512. https://doi. org/10.1108/14684520510628891

Tremblay, D., 2004, Virtual communities of practice: Towards new modes of learning and knowledge creation?, Tele-universite, Quebec, viewed 11 May 2018, from http://www.cjc-online.ca/journal/article/viewArticle/pdf

Van Winkelen, C., 2003, Inter-organisational communities of practice, viewed 11 May 2018, from http://www.ibrarian.net/navon/paper/Inter_organizational communities_of_practice_Dr_.pdf?paperid $=157581$

Vuori, V. \& Okkonen, J., 2012, 'Refining information and knowledge by social media applications: Adding value by insight', A Journal: Vine 42(1), 117-128. https://doi. org/10.1108/03055721211207798

Warden, S.C., 2010, Reader: Writing an academic article, research report or research proposal, Unpublished Reader - BIS/OMT research seminar, Cape Peninsula University of Technology, Cape Town.

Wenger, E., McDermott, R. \& Snyder, W.M., 2002, Cultivating communities of practice A guide to managing knowledge, Harvard business school press, Boston, MA.

Yin, R.K., 2003, Case study research: Design and methods. SAGE publications, Inc.: London.

Zheng, T.T., 2017, 'A literature review on knowledge sharing', Open Journal of Social Sciences 5(1), 51-58. https://doi.org/10.4236/jss.2017.53006 